\title{
Enhanced DTC induction motor drives for THD minimization performance improvement with multilevel inverter
}

\author{
Siong Kai Chien ${ }^{1}$, Sy Yi Sim ${ }^{1}$, Wahyu Mulyo Utomo ${ }^{2}$, Sie Long Kek ${ }^{3}$, Farahiyah Mustafa ${ }^{1}$, \\ Nor Aira Zambri ${ }^{1}$, Alvin John Lim Meng Siang ${ }^{4}$, Gia Yi Sim ${ }^{2}$ \\ ${ }^{1}$ Faculty of Engineering Technology, University Tun Hussein Onn Malaysia, Johor, Malaysia \\ ${ }^{2}$ Faculty of Electrical and Electronic Engineering, University Tun Hussein Onn Malaysia, Johor, Malaysia \\ ${ }^{3}$ Faculty of Applied Sciences and Technology, University Tun Hussein Onn Malaysia, Johor, Malaysia \\ ${ }^{4}$ Faculty of Civil Engineering and Built Environment, University Tun Hussein Onn Malaysia, Johor, Malaysia
}

\begin{abstract}
Article Info
Article history:

Received Nov 1, 2021

Revised Jan 15, 2022

Accepted Jan 22, 2022

Keywords:

Direct torque control

Multilevel inverter

Total harmonic distortion

ABSTRACT

Direct torque control (DTC) is a method applied in induction motor (IM) drives to control the speed and torque of IM accurately and independently without feedback signal. However, in fast fourier transform (FFT) analysis, the total harmonic distortion (THD) of the IM drives is high in DTC method with conventional inverter (CI). Therefore, the purpose of this study is to minimize the THD without affecting the drive's performance. A DTC IM drive with multilevel inverter (MLI) is proposed in this study to reduce THD and preserve good speed and torque response of IM simultaneously. DTC IM drive with proposed MLI based THD minimization has several advantages over the DTC IM drive with CI, including higher generated output voltage with low distortion, operate under low switching frequency, and work with renewable energy. In order to prove the effectiveness of the proposed MLI based THD minimization in DTC IM drive, MATLAB Simulink is used to investigate the response of the IM drive and THD under different operating condition. From this study, proposed MLI based THD minimization DTC IM drive is able to reduce THD with a maximum of $13 \%$ in low speed operation as compared to DTC IM drive with CI.
\end{abstract}

This is an open access article under the CC BY-SA license.

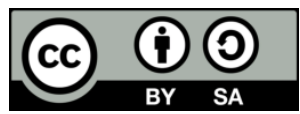

\section{Corresponding Author:}

\section{Sy Yi Sim}

Faculty of Engineering Technology, University Tun Hussein Onn Malaysia

Pagoh Campus, 84600 Panchor, Johor, Malaysia

Email: sysim@uthm.edu.my

\section{INTRODUCTION}

Induction motor (IM) is an alternating current (AC) electric motor that is extensively used in household appliances and manufactory industrial that consume about 54\% of the total consumed electrical energy [1]-[4]. IM consist of two parts which are stator and rotor. The magnetic field of the stator winding induces the magnetic flux in the rotor to produce rotating torque and rotate the mechanical load devices that are connected to the rotor by using the shaft [5], [6]. Basically, the efficiency of IM is high when operation of IM is at rated speed and load torque conditions [7]. However, for a variable speed and load operation, the application of the IM at rated flux will cause the efficiency of IM to decrease dramatically [8], [9]. Therefore, to achieve the efficiency optimization of the IM drive system at partial load, it is important to obtain the flux level that minimizes the total motor losses [10].

IM drives that having speed control has enormous use in the industry sector [11], [12]. These IM drives occupy more than $75 \%$ of the load in the industry of any country [13], [14]. High performance IM drives application needs high efficiency, low cost and simple control circuitry for the complete speed range 
[15], [16]. There are two different approaches for IM drives efficiency optimization. The first approach uses analytical computation of motor losses to optimize the efficiency that is named as losses model controller method. This method has the main advantage of not requiring additional hardware but needs accurate knowledge of motor parameters. The second approach will gradually search the flux level to obtain maximum efficiency, named as online or search efficiency optimization control method. This method has the advantage that it is completely insensitive to motor parameters variation.

Total harmonic distortion (THD) of IM drive is significant since minimization of THD will increase the efficiency of the motor drive [17]-[19]. THD variation analysis of current source inverter fed electric motor drive system during various fault conditions is conducted in [20] and it shows that during a fault condition, the THD of motor drive increases [21]. THD minimization can be done using various methods, out of which multi-level inverter (MLI) fed IM drive preferably used to reduce THD in IM drive [22]-[24]. This is because MLI are good power quality and have higher voltage capability [25]-[27]. MLI not only achieves a higher power rating but also enables the use of renewable energy sources [28], [29].

A three-phase DTC IM drives with and without MLI is presented in this paper to validate the proposed THD minimization of the motor drive at different operating speeds with variable load applied by using MATLAB Simulink. The simulation testing for the proposed MLI based DTC and conventional inverter (CI) IM drive is conducted and compared at low speed (300 rpm), medium speed (850 rpm) and high speed $(1400 \mathrm{rpm})$ with variable load applied to IM under the same conditions. This paper has been divided into few sections. In section 2 research method of this project is discussed. Section 3 will discuss the simulation result of the proposed MLI based THD minimization DTC IM drives obtained from MATLAB/Simulink. Section 4 will conclude the findings of the proposed MLI based DTC in THD minimization performance improvement.

\section{ENHANCED MLI BASED DTC FOR THD MINIMIZATION}

The aim of this study is to apply MLI in DTC IM drive that can reduce the THD of the drive system. The block diagram of the proposed MLI based THD minimization DTC IM drive is illustrated in Figure 1. Figure 2 and Figure 3 show the Simulink model of the DTC IM drive with conventional two-level inverter and the proposed five-level MLI based THD minimization DTC IM drive, respectively.

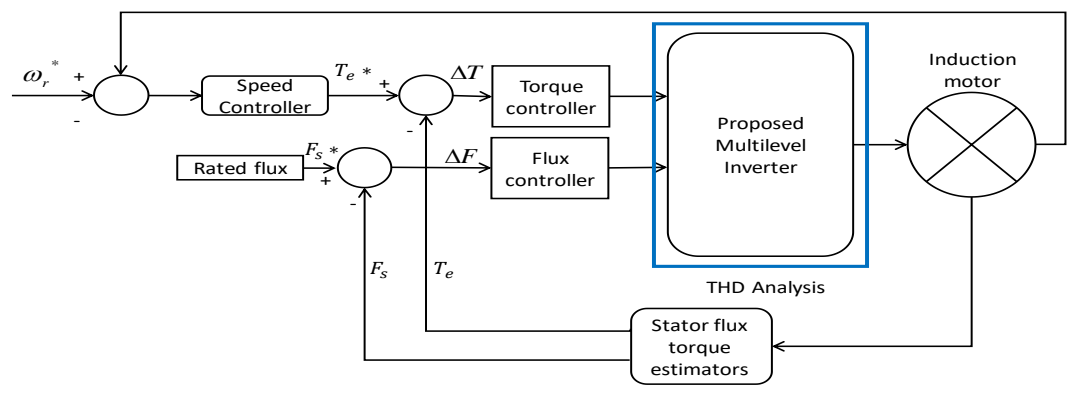

Figure 1. Block diagram of proposed MLI based THD minimization DTC IM drive

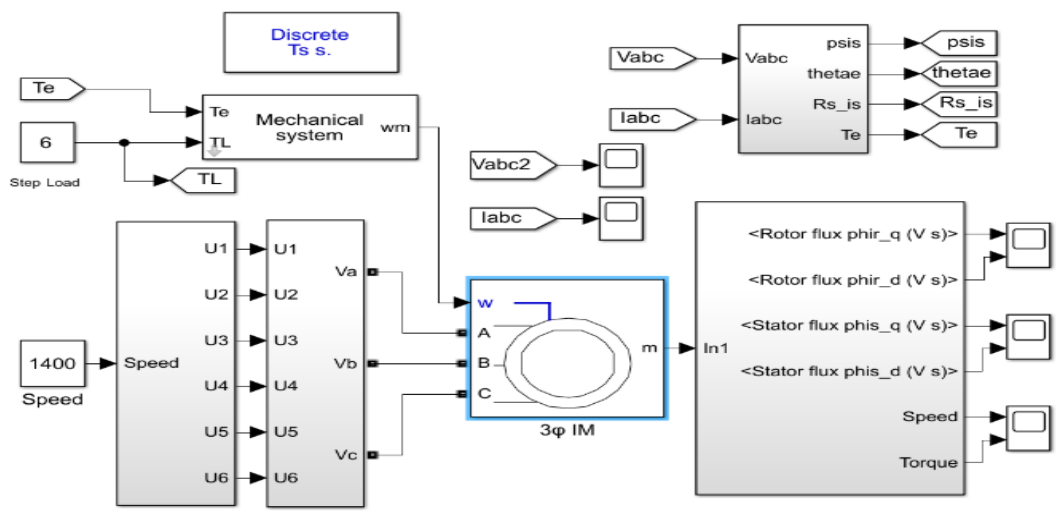

Figure 2. DTC IM with CI 


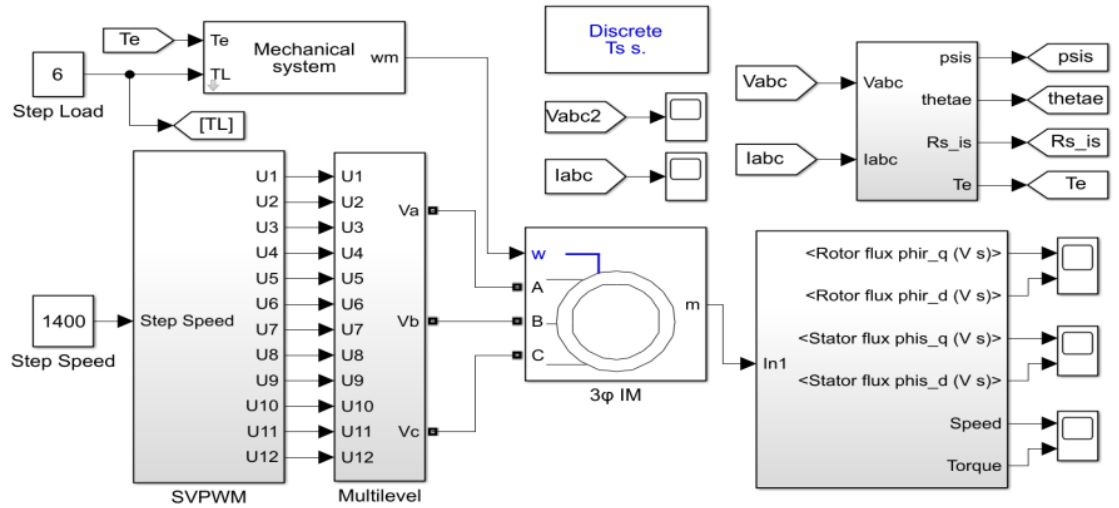

Figure 3. Proposed MLI based THD Minimization DTC IM drive

A conventional two-level inverter consists of an equal amount voltage source and many switches for controlling voltage or current. For high power and high voltage applications, using a conventional twolevel inverter at high frequency results in switching losses and constraints of the power device ratings. On the other hand, the proposed five-level MLI based THD minimization DTC IM drive gives a better dynamic performance as compared to CI based DTC.

Theoretically, MLI can achieve THD minimization in DTC IM drive. The higher the level of MLI in DTC IM drive, the better the performance of MLI in THD minimization. However, increase the level of MLI in DTC IM drive will increase the drive system complexity. To verify the effectiveness of MLI in THD minimization for DTC IM drive, MATLAB Simulink is used for testing under different conditions.

\section{RESULTS AND DISCUSSION}

Table 1 shows the specification of IM used in this study. The proposed MLI based DTC will be tested along with the conventional inverter (CI) based DTC under three different conditions, which are step load torque variation with constant low speed $(300 \mathrm{rpm})$ conditions, medium speed $(850 \mathrm{rpm})$ conditions, and high rotating speed $(1400 \mathrm{rpm})$ conditions. In each different MATLAB/Simulink testing, the corresponding result of THD, speed response, and load torque response is observed and compared.

Table 1. IM specification

\begin{tabular}{cc}
\hline Specification of IM & Parameters \\
\hline Number of phases & 3 \\
Mechanic power & $5.4 \mathrm{HP}, 4 \mathrm{KW}$ \\
Rated voltage & $400 \mathrm{~V}$ \\
Rated frequency & $50 \mathrm{~Hz}$ \\
Rotor speed & $1430 \mathrm{rpm}$ \\
Number of poles & 4 \\
\hline IM parameters and types of frames \\
Reference frame & Stationary \\
Stator resistance & $1.405 \Omega$ \\
Rotor resistance & $1.395 \Omega$ \\
Stator inductance & $5839 \mathrm{mH}$ \\
Rotor inductance & $5839 \mathrm{mH}$ \\
\hline
\end{tabular}

In Matlab Simulink, the load on IM is initially set at $0 \mathrm{Nm}$, and start from $2 \mathrm{~s}$, the load on IM increase to $6 \mathrm{Nm}$. The load on IM continues to increase to $12 \mathrm{Nm}$ after $6 \mathrm{~s}$ and decrease to $-6 \mathrm{Nm}$ after $7 \mathrm{~s}$. And lastly, increase back to $6 \mathrm{Nm}$ after $9 \mathrm{~s}$. In step load testing, the resulting THD obtained are compared between the DTC IM drive with CI and the proposed MLI based THD minimization DTC IM drive. Figure 4 (a) and Figure 4 (b) show the results of the proposed MLI based DTC compared with the CI based DTC, respectively, with step load and fixed slow speed $(300 \mathrm{rpm})$. Table 2 shows the FFT result of current $I_{a}, I_{b}$ and $I_{c}$ respectively and Figure 5 (a) and Figure 5 (b) shows the THD reduction comparison in three-phase line current, $I_{a}$ in MATLAB Simulink. Based on the THD reading obtained from both Figure 5 (a) and Figure 5 (b), it is obvious that the THD is reduced by $12.87 \%$ in IM drive with proposed MLI as compared to IM drive with CI. 

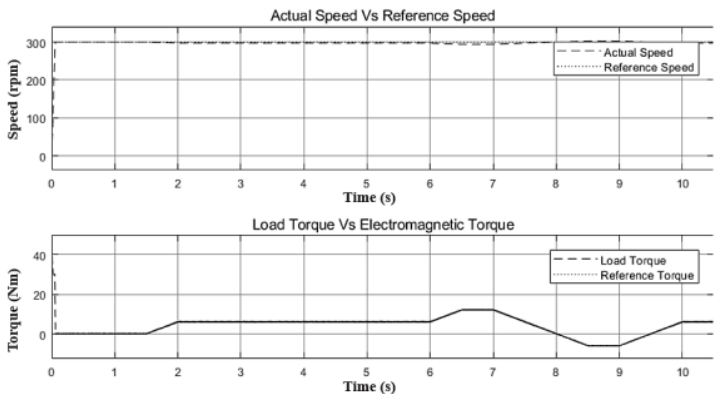

(a)
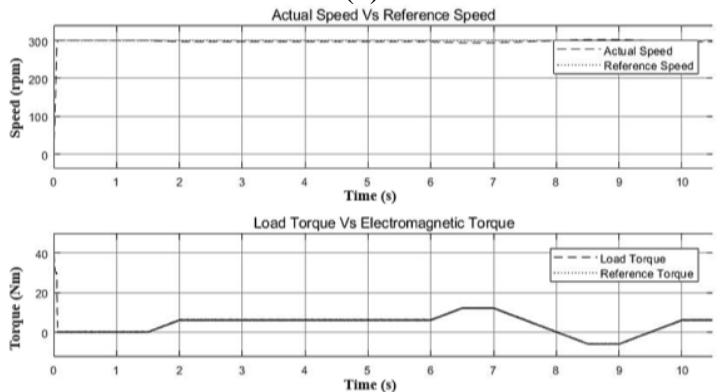

(b)

Figure 4. Speed and load torque performance of proposed MLI based THD minimization DTC IM drive at low speed (a) DTC IM drive with CI and (b) DTC IM drive with MLI

Table 2. THD of DTC IM drives with and without MLI corresponding to step load and 300rpm fixed speed

\begin{tabular}{ccc}
\hline Type of Inverter & CI-DTC (\%) & MLI-DTC (\%) \\
\hline$I_{a}$ & 67.03 & 54.16 \\
$I_{b}$ & 75.68 & 61.22 \\
$I_{c}$ & 76.82 & 62.76 \\
\hline
\end{tabular}

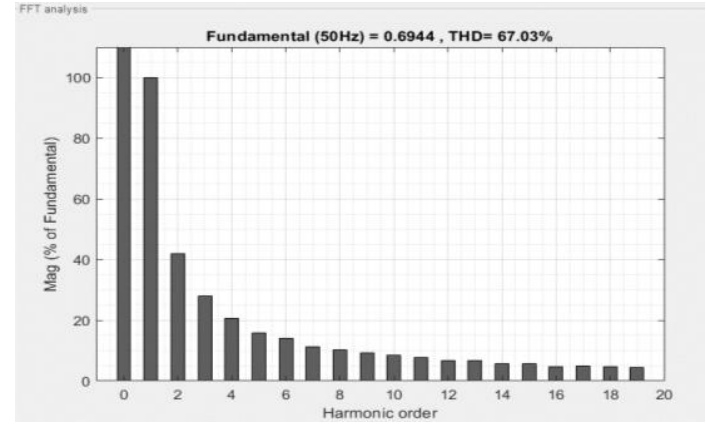

(a)

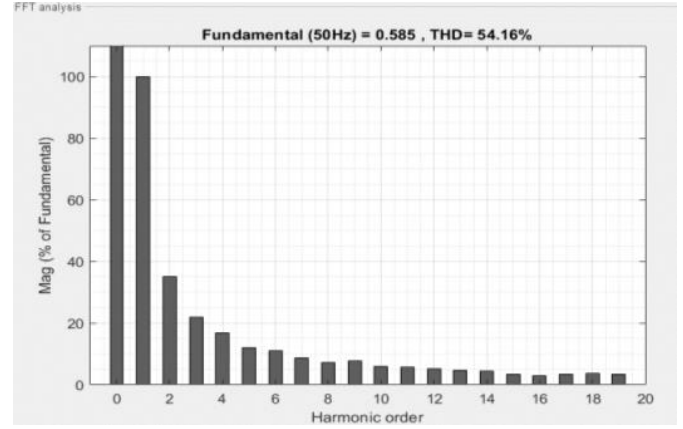

(b)

Figure 5. FFT result of current, $I_{a}$ with step load at slow speed (300 rpm) (a) DTC IM drive with CI and (b) DTC IM drive with MLI

Figure 6 (a) and Figure 6 (b) show the results of the proposed MLI based DTC compared with the CI based DTC with step load and fixed medium speed (850rpm), respectively. Table 3 shows the FFT result of current $I_{a}, I_{b}$ and $I_{c}$ respectively and Figure 7 (a) and Figure 7 (b) shows the THD reduction comparison in three-phase line current, $I_{a}$ in MATLAB Simulink. From Figure 7 (a) and Figure 7 (b), THD is reduced by $13.17 \%$ in IM drive with proposed MLI as compared to IM drive with CI.

Figure 8 (a) and Figure 8 (b) show the results of the proposed MLI based DTC compared with the CI based DTC with step load and fixed high speed $(1400 \mathrm{rpm})$, respectively. Table 4 shows the FFT result of current $I_{a}, I_{b}$ and $I_{c}$ respectively and Figure 9 (a) and Figure 9 (b) shows the THD reduction comparison in 
three-phase line current, $I_{a}$ in MATLAB Simulink. By referring to Figure 9 (a) and Figure 9 (b), the THD is reduced by $1.43 \%$ in IM drive with proposed MLI as compared to IM drive with CI.
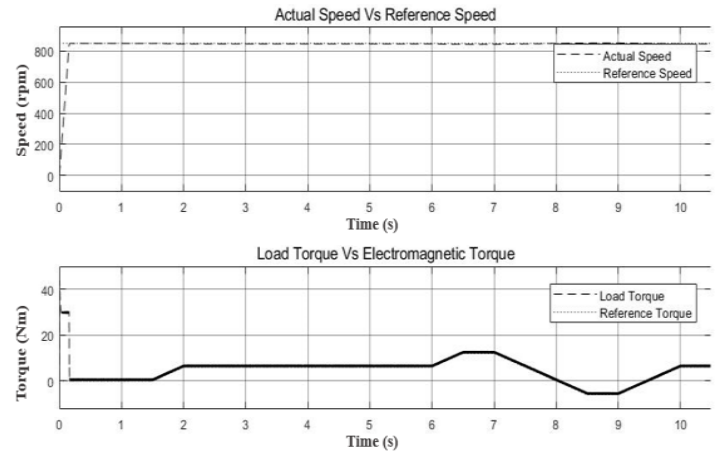

(a)
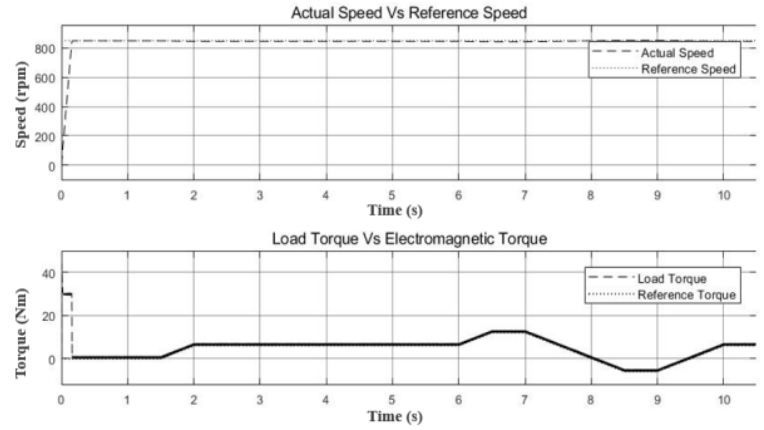

(b)

Figure 6. Speed and load torque performance of proposed MLI based THD minimization DTC IM drive at medium speed (a) DTC IM drive with CI and (b) DTC IM drive with MLI

Table 3. THD of DTC IM drives with and without MLI corresponding to step load and $850 \mathrm{rpm}$ fixed speed

\begin{tabular}{ccc}
\hline Type of Inverter & CI-DTC (\%) & MLI-DTC (\%) \\
\hline$I_{a}$ & 40.01 & 26.84 \\
$I_{b}$ & 56.55 & 45.59 \\
$I_{c}$ & 45.49 & 31.57 \\
\hline
\end{tabular}

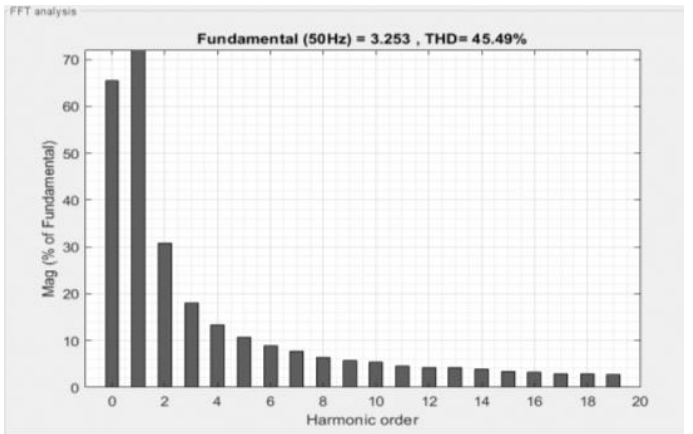

(a)

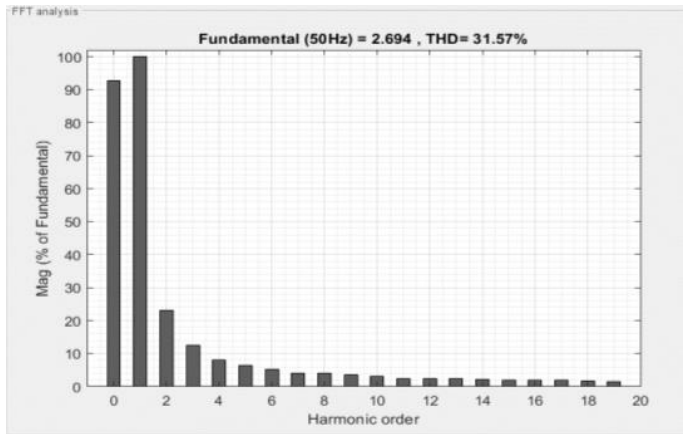

(b)

Figure 7. FFT result of current, $I_{c}$ with step load at medium speed (850 rpm) (a) DTC IM drive with CI and (b) DTC IM drive with MLI
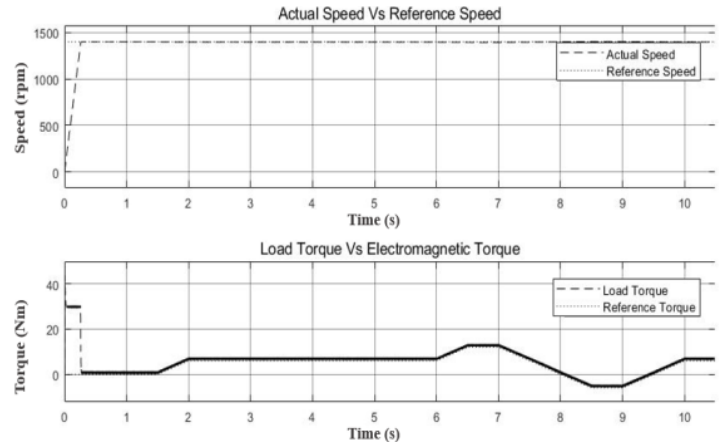

(a)
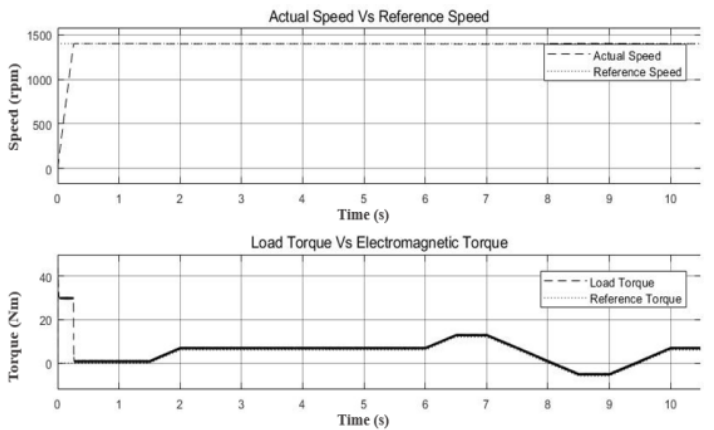

(b)

Figure 8. Speed and load torque performance of proposed MLI based THD minimization DTC IM drive at high speed (a) DTC IM drive with CI and (b) DTC IM drive with MLI 
Table 4. THD of DTC IM drives with and without MLI corresponding to step load and $1400 \mathrm{rpm}$ fixed speed

\begin{tabular}{ccc}
\hline Type of Inverter & CI-DTC (\%) & MLI-DTC (\%) \\
\hline$I_{a}$ & 11.23 & 9.80 \\
$I_{b}$ & 5.93 & 5.18 \\
$I_{c}$ & 9.53 & 8.58 \\
\hline
\end{tabular}

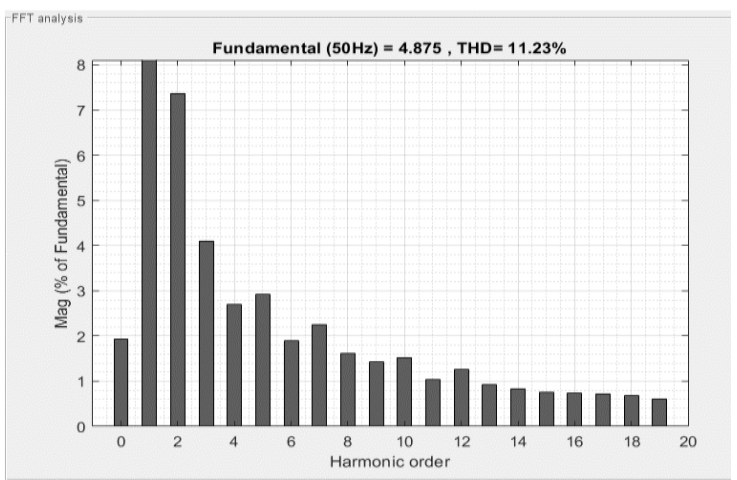

(a)

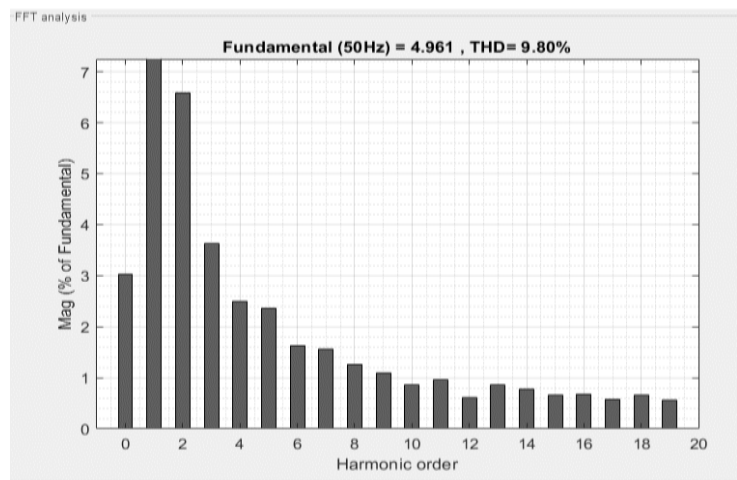

(b)

Figure 9. FFT result of current, $I_{a}$ with step load at high speed (1400rpm) (a) DTC IM drive with CI and

(b) DTC IM drive with MLI

The THD for the proposed MLI based THD minimization DTC IM drive and DTC IM drive with CI with step load at slow speed, medium speed and high rotating speed of IM are summarised in Table 5. From the result obtained, with the proposed MLI based THD minimization DTC IM drive, the THD of the IM drive is significantly reduced as compared with CI based DTC IM drive. THD is minimum when IM operates at rated condition (1400 rpm). From this study, the IM's speed and load torque are consistent in an outstanding performance with the proposed MLI based THD minimization DTC IM drive as shown in Figure 4, Figure 6 and Figure 8 for various speed load conditions. Furthermore, based on the results obtained, the THD of the DTC IM drive can be reduced at least $0.75 \%$ at rated speed and a maximum of $14.46 \%$ at low speed with the proposed MLI based THD minimization DTC IM drive.

Table 5. THD of DTC IM drives with and without MLI corresponding to step load and different fixed speed

\begin{tabular}{cccccc}
\hline $\begin{array}{c}\text { Speed (rpm) } \\
\text { Type of inverter }\end{array}$ & $\begin{array}{c}\text { Conventional } \\
\text { inverter }\end{array}$ & Proposed MLI & $\begin{array}{c}\text { THD }(\%) \\
\text { Conventional } \\
\text { inverter }\end{array}$ & $\begin{array}{c}850 \\
\text { Proposed MLI }\end{array}$ & $\begin{array}{c}\text { Conventional } \\
\text { inverter }\end{array}$ \\
\hline$I_{a}$ & 67.03 & 54.16 & 40.01 & 26.84 & 11.23 \\
$I_{b}$ & 75.68 & 61.22 & 56.55 & 45.59 & 5.93 \\
$I_{c}$ & 76.82 & 62.76 & 45.49 & 31.57 & 9.80 \\
\hline
\end{tabular}

\section{CONCLUSION}

In conclusion, with the proposed MLI based THD minimization DTC IM drive applied in this study, the simulation result shows that the appropriate operation of the MLI results in reducing the THD of the motor drive system. The MATLAB Simulink result of CI based DTC IM drive offers the robustness and simplicity of the motor drive system, but there are high switching loss and torque ripples as compared to the proposed MLI based THD minimization DTC IM drive. For the proposed MLI based THD minimization DTC IM drive, it offers advantages in reducing the switching losses and torque ripples, but MLI will increase the drive system complexity. From this study, MATLAB Simulink results of DTC IM drive with the proposed MLI based THD minimization shows that the THD of the DTC IM drive with fixed speed and step load condition can be lowered approximately at an average $13.80 \%$ for low speed operation, $12.68 \%$ for medium speed operation and $1.04 \%$ for high speed operation. 


\section{ACKNOWLEDGEMENTS}

The authors would like to acknowledge Universiti Tun Hussein Onn Malaysia (UTHM) and the Ministry of Higher Education (MOHE) for the financial support for this study under Fundamental Research Grant Scheme (FRGS) Vot No. FRGS/1/2018/TK10/UTHM/03/8.

\section{REFERENCES}

[1] M. D. Kumar, S. F. Kodad, and B. Sarvesh, "Simplified Fault Detection Algorithm for Voltage Source Fed Induction Motor," Mater. Today Proc., vol. 5, no. 1, pp. 1401-1410, 2018.

[2] H. R. Khoei and E. F. Shahraki, "Fuzzy Logic Based Direct Power Control of Induction Motor Drive," Bull. Electr. Eng. Informatics, vol. 5, no. 3, pp. 296-306, Sep. 2016.

[3] N. Kiran, "Indirect Vector Control of Three Phase Induction Motor using PSIM," Bull. Electr. Eng. Informatics, vol. 3, no. 1, pp. 15-24, Mar. 2014.

[4] C. Laoufi, Z. Sadoune, A. Abbou, and M. Akherraz, "New model of electric traction drive based sliding mode controller in field-oriented control of induction motor fed by multilevel inverter," Int. J. Power Electron. Drive Syst., vol. 11, no. 1, pp. 242-250, Mar. 2020.

[5] J. Wadibhasme, S. Zaday, and R. Somalwar, "Review of various methods in improvement in speed, power \&amp; efficiency of induction motor," in 2017 International Conference on Energy, Communication, Data Analytics and Soft Computing (ICECDS), 2017, pp. 3293-3296.

[6] V. T. Ha, T. T. Minh, N. T. Lam, and N. H. Quang, "Experiment based comparative analysis of stator current controllers using predictive current control and proportional integral control for induction motors," Bull. Electr. Eng. Informatics, vol. 9, no. 4, pp. 1662-1669, Aug. 2020.

[7] W. M. Utomo et al., "An improved DTC of an induction motor drive with neural network controller," Int. J. Mech. Mechatronics Eng., vol. 14, no. 2, pp. 54-59, 2014.

[8] S. Massoum, A. Meroufel, A. Massoum, and W. Patrice, "DTC based on SVM for induction motor sensorless drive with fuzzy sliding mode speed controller," Int. J. Electr. Comput. Eng., vol. 11, no. 1, pp. 171-181, Feb. 2021

[9] N. Goel, S. Chacko, and R. N. Patel, "A parameter less stochastic optimization technique for tuning of speed PI controller of DTC induction motor drive," IAES Int. J. Robot. Autom., vol. 8, no. 2, pp. 105-112, Jun. 2019.

[10] W. M. Utomo, S. Y. Sim, Z. A. Haron, A. A. Bohari, and N. M. Zin, "ONLINE ADAPTIVE FLUX CONTROL FOR SPACE VECTOR PWM-DTC IM DRIVES TOWARDS OPTIMUM EFFICIENCY DESIGN,” J. Eng. Appl. Sci., vol. 10, no. 19, pp. 9099-9105, 2015.

[11] M. R, S. B. P., B. H. Satheesh, and D. M. N, "Low Speed Estimation of Sensorless DTC Induction Motor Drive Using MRAS with Neuro Fuzzy Adaptive Controller," Int. J. Electr. Comput. Eng., vol. 8, no. 5, pp. 2691-2702, Oct. 2018.

[12] J. Sabarad and G. H. Kulkarni, "Novel switching technique for five leg inverter in dual motor control," Indones. J. Electr. Eng. Comput. Sci., vol. 19, no. 2, pp. 644-651, Aug. 2020.

[13] S. S. Yi et al., "Loss minimization DTC electric motor drive system based on adaptive ANN strategy," Int. J. Power Electron. Drive Syst., vol. 11, no. 2, pp. 618-624, Jun. 2020.

[14] W. M. Utomo, S. S. Yi, Y. M. Y. Buswig, Z. A. Haron, A. A. Bakar, and M. Z. Ahmad, "Voltage tracking of a DCDC flyback converter using neural network control," Int. J. Power Electron. Drive Syst., vol. 2, no. 1, pp. 35-42, Mar. 2012.

[15] E. Lotfi, M. Elharoussi, and E. Abdelmounim, "VHDL design and FPGA implementation of direct torque control for induction machines," Bull. Electr. Eng. Informatics, vol. 10, no. 3, pp. 1220-1231, Jun. 2021.

[16] A. N. Abdullah and M. H. Ali, "Direct torque control of IM using PID controller," Int. J. Electr. Comput. Eng., vol. 10, no. 1, pp. 617-625, Feb. 2020.

[17] A. Ramesh, O. C. Sekhar, and M. S. Kumar, "A Novel Three Phase Multilevel Inverter with Single De Link For Induction Motor Drive Applications," Int. J. Electr. Comput. Eng., vol. 8, no. 2, pp. 763-770, Apr. 2018.

[18] H. A. Mohamed and H. M. D. Habbi, "Power quality of dual two-level inverter fed open end winding induction motor," Indones. J. Electr. Eng. Comput. Sci., vol. 18, no. 2, pp. 688-697, 2020.

[19] M. Khanfara, R. El Bachtiri, M. Boussetta, and K. El Hammoumi, "A multicarrier PWM technique for five level inverter connected to the grid," Int. J. Power Electron. Drive Syst., vol. 9, no. 4, pp. 1774-1783, 2018.

[20] V. Sharma and G. Mendiratta, "Harmonic analysis of CSI-fed induction motor drive," 2014 Int. Conf. Comput. Sustain. Glob. Dev. INDIACom 2014, pp. 321-325, 2014.

[21] M. A. Al-Yoonus and O. S. Al-Deen Alyozbaky, "Detection of internal and external faults of single-phase induction motor using current signature," Int. J. Electr. Comput. Eng., vol. 11, no. 4, pp. 2830-2841, Aug. 2021.

[22] S. Y. Sim et al., "Enhance cascaded H-bridge multilevel inverter with artificial intelligence control," Indones. J. Electr. Eng. Comput. Sci., vol. 11, no. 1, pp. 105-112, 2018.

[23] W. M. W. M. Utomo et al., "Modeling of A Single Phase 7-Level Cascaded H-Bridge Multilevel Inverter," Int. J. Eng. Technol., vol. 7, no. 2, pp. 327-330, 2018.

[24] A. Agrawal, R. S. Lodhi, and P. Nema, "Indirect vector control for induction motor drive using two level and five level inverter," Int. J. Appl. Power Eng., vol. 8, no. 2, pp. 134-144, Aug. 2019.

[25] P. V. Kapoor and M. M. Renge, "Improved Performance of Modular Multilevel Converter for Induction Motor Drive," Energy Procedia, vol. 117, pp. 361-368, 2017.

[26] W. M. Utomo et al., "Voltage tracking of bridgeless PFC cuk converter using PI controller," Int. J. Power Electron. Drive Syst., vol. 11, no. 1, pp. 367-373, Mar. 2020.

[27] D. Karthikeyan, K. Vijayakumar, D. S. Kumar, and D. Krishnachaitanya, "Mathematical analysis of cost function 
and reliability condition for new proposed multilevel inverter topology,” Indones. J. Electr. Eng. Comput. Sci., vol. 20, no. 2, pp. 654-661, Nov. 2020.

[28] A. Ansari, S. Jain, S. P. Phulambikar, and S. Gupta, "Performance and Analysis with Power Quality Improvement with Induction Motor in Electric Drive," Int. J. Eng. Tech. Res., vol. 2, no. 10, pp. 30-34, 2014.

[29] R. K. Bhukya and P. S. Kumar, "Simplified down sampling factor based modified SVPWM technique for cascaded inverter fed induction motor drive," Int. J. Adv. Appl. Sci., vol. 9, no. 1, pp. 20-26, Mar. 2020.

\section{BIOGRAPHIES OF AUTHORS}

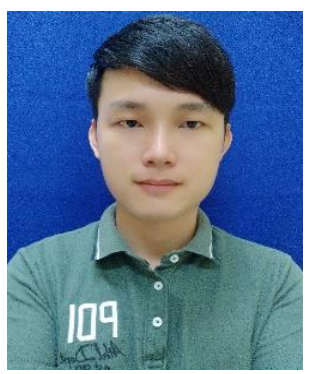

Siong Kai Chien (D) $8 \mathrm{~S}$ SC $\mathrm{P}$ received B.Eng. (Hons.) in electronic engineering from Universiti Tun Hussein Onn Malaysia, in 2019. He is currently a research assistant with the Department of Electrical Engineering Technology, Faculty of Engineering Technology, Universiti Tun Hussein Onn Malaysia. His current research interests include motor drive control and artificial intelligence control. He can be contacted at email: hn180036@siswa.uthm.edu.my

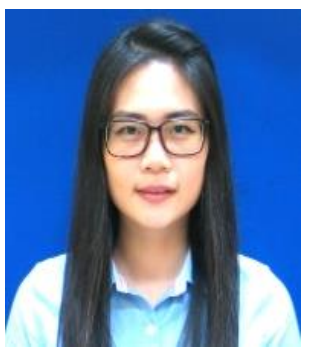

Sy Yi Sim (iD SC SC P received B.Eng. (Hons.) and PhD degrees in electrical engineering from Universiti Tun Hussein Onn Malaysia, in 2012 and 2016, respectively. She is currently a Lecturer with the Department of Electrical Engineering Technology, Faculty of Engineering Technology, Universiti Tun Hussein Onn Malaysia. Her current research interests include the area of power electronics, motor drives control, renewable energies and artificial intelligence control. She can be contacted at email: sysim@uthm.edu.my

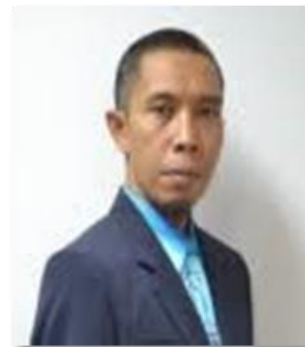

Wahyu Mulyo Utomo (D) S SC P, is currently working as an Associate Professor in the Department of Electrical Engineering, Faculty of Electrical and Electronic Engineering, Universiti Tun Hussein Onn Malaysia. He received his M.Sc. from Institute Sepuluh Nopember Surabaya, Indonesia in 2000 and Ph.D. from Universiti Teknologi Malaysia, Johor, Malaysia in 2007. His research interests include Power Electronics and Motor Drives Control. He can be contacted at email: wahyu@uthm.edu.my.

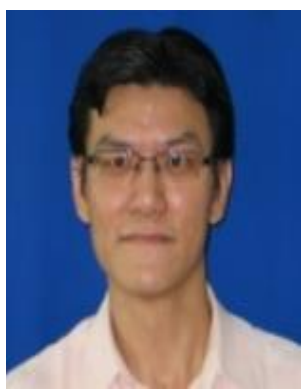

Sie Long Kek (D) 8d SC P is currently working as a Senior Lecturer in the Department of Mathematics and Statistics, Faculty of Applied Sciences and Technology, Universiti Tun Hussein Onn Malaysia. He received his M.Sc. and Ph.D. in mathematics from Universiti Teknologi Malaysia, Johor, Malaysia in 2002 and 2011, respectively. He was a research associate at the Curtin University of Technology in 2009 during his Ph.D. study. His research interests include optimization and control, operation research and management science, modeling and simulation, parameter estimation, Kalman filtering, and computational mathematics. He can be contacted at email: slkek@uthm.edu.my.

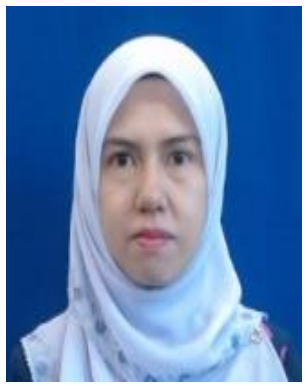

Nor Aira Zambri (D) IS SC P received B.Eng. (Hons.) in electrical and electronic engineering from Universiti Kebangsaan Malaysia, M.Eng in electrical power engineering from Universiti Teknologi Malaysia and $\mathrm{PhD}$ degrees in the same field from Universiti Kebangsaan Malaysia, in 2007, 2009 and 2014, she is currently a senior lecturer at the Faculty of Engineering Technology, Universiti Tun Hussein Onn Malaysia. Her current research interests include Renewable Energy, Photovoltaic (PV) Systems. She can be contacted at email: aira@uthm.edu.my. 

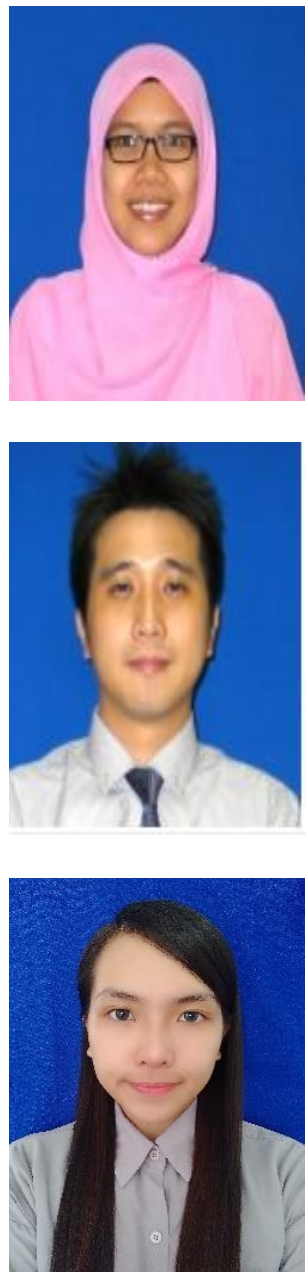

Farahiyah Mustafa (D) SC S received B.Eng. (Hons.), M.Eng and PhD degrees in electrical engineering from Universiti Teknologi Malaysia, in 2007, 2010 and 2014, respectively. She is currently a senior lecturer at the Faculty of Engineering Technology, Universiti Tun Hussein Onn Malaysia. Her current research interests include, Renewable Energies, Power Electronics and Electronic Devices. She can be contacted at email: farahiyah@uthm.edu.my.

Alvin John Lim Meng Siang (D) $\mathrm{SC}$ P pursued his studies in civil engineering and graduated in 2011 with a first-class Degree in Civil Engineering with Honours. He then continued and accomplished his Doctor of Philosophy (PhD) in Geotechnical Engineering in 2014. He is now a Lecturer in Universiti Tun Hussien Onn Malaysia and is focused in various teaching and research activities in Sustainable Development and Data Science. He can be contacted at email: alvin@uthm.edu.my.

Gia Yi Sim (D) SC P received B.Eng. (Hons.) in electric engineering from Universiti Tun Hussein Onn Malaysia, in 2018. She is currently a research assistant with the Department of Electrical Engineering, Faculty of Electric and Electronic Engineering, Universiti Tun Hussein Onn Malaysia. Her current research interests include renewable energy and power transmission. She can be contacted at email: ge180097@siswa.uthm.edu.my. 